\title{
CLONING OF A NOVEL XYLANASE GENE FROM A NEWLY ISOLATED FUSARIUM SP. Q7-31 AND ITS EXPRESSION IN ESCHERICHIA COLI
}

\author{
Zhan-Ling Xie ${ }^{1,2, *}$, Hai-Yan Gao ${ }^{2}$, Qian Zhang ${ }^{2}$, Huan Wang ${ }^{2}$, Ying Liu ${ }^{1}$ \\ ${ }^{1}$ Gansu Agricultural University, Lanzhou 730000 , China; ${ }^{2}$ Qinghai University, Xining 810016, China.
}

Submitted: March 31, 2011; Returned to authors for corrections: May 06, 2011; Approved: August 30, 2011.

\begin{abstract}
A strain of Q7-31 was isolated from Qinghai-Tibet Plateau and was identified as Fusarium sp. based on its morphological characteristics and ITS rDNA gene sequence analysis. It has the highest capacity of degrading cell wall activity compared with other 11 strains. To do research on its xylanase activity of Fusarium sp. Q7-31 while the degrading the rice cell walls, the complete gene xyn8 that encodes endo-1, 4$\beta$-xylanase secreted by Fusarium sp. Q7-31 was cloned and sequenced. The coding region of the gene is separated by two introns of 56bp and 55bp. It encodes 230 amino acid residues of a protein with a calculated molecular weight of $25.7 \mathrm{kDa}$. The animo acids sequence of $x y n 8$ gene has higher similarity with those of family 11 of glycosyl hydrolases reported from other microorganisms. The nature peptide encodeing cDNA was subcloned into pGEX5x-1 expression vector. The recombinant plasmid was expressed in Escherichia coli BL21-CodonPlus (DE3)-RIL, and xylanase activity was measured. The expression fusion protein was identified by SDS-PAGE and Western blotting, a new specific band of about 52kDa was identified when induced by IPTG. Enzyme activity assay verified the recombinants proteins as a xylanase. A maxium activity of $2.34 \mathrm{U} / \mathrm{mg}$, the xylanase had optimal activity at $\mathrm{pH} 6.0$ and temperature $40^{\circ} \mathrm{C}$.
\end{abstract}

Key words: xylanase; Gene cloning; Fusarium sp.;

\section{INTRODUCTION}

Fusarium sp., which is a cosmopolitan soil borne filamentous fungus, is an anamorphic species. Some of them can produce several enzymes that can act on pectin and cellulose components of cell wall (5). Recently, scientists pay more attention to them because some strains from Fusarium oxysporum can ferment cellulose into bioethanol by one step (22).
Endo- $\beta-1,4$-xylanases(EC 3.2.1.8) are secreted by a number of plant pathogenic fungus. Walton (24) described that those xylanses may play a role during infection. Fusarium sp. also secrets a number of xylanases, at least five xylanases, Xyl1, Xyl2, Xyl3, Xyl4, Xyl5, xylanase of low molecular weight have been found from Fusarium sp. (1,2,3,4,5,6,8,9,10,14,15), from xyl1 to here, we reported a new xylanase gene from Fusarium sp. Q7-31. 


\section{MATERIALS AND METHODS}

\section{Reagents}

PCR Purification Kit, DNA Gel Extraction Kit, RNA PCR Kit (AMV) Ver. 3.0, IPTG, X-gal, Taq polymerase, restriction enzymes were purchased from the TaKaRa Bio-technology (Dalian, China) Co. Ltd., M-MLV reverse transcriptase was the product of Promega (Madison, WI). The SMART ${ }^{\mathrm{TM}}$ PCR cDNA Synthesis Kit was purchased from ClonTech (Palo Alto, CA). Trizol reagent and culture media were obtained from Invitrogen and Shanghai Sangon Co., Ltd., respectively. All other chemicals were of analytical grade. GST Monoclonal Antibody, Secondary Antibody and DAB Horseradish Peroxidase Color Development Kit were purchased from Sigma-Aldrich Co. Ltd.

\section{Isolation of Fusarium sp. Q7-31}

Fusarium sp. Q7-31 were isolated from fruiting bodies of Morchella sp. and screened to pure isolates through a series of subcultures on agar plates. The screening medium consisted of $0.6 \%$ peptone, $0.1 \% \mathrm{~K}_{2} \mathrm{HPO}_{4}, 0.05 \% \mathrm{MgSO}_{4} \cdot 7 \mathrm{H}_{2} \mathrm{O}$, and $1 \%$ glucose ( $\mathrm{pH} 7.0)$. The plates were incubated at $28^{\circ} \mathrm{C}$ for 3 to 5 d. Colonies that grew well were then subcultured to fresh agar plates. A loop-full of hyphae was removed from uniform colonies and inoculated into a basic liquid medium (BLM) with the same composition as the screening medium. These liquid cultures were maintained at $28^{\circ} \mathrm{C}$ on a rotary shaker with $100 \times \mathrm{g}$. For storage, the fungus strains were inoculated on potato dextrose agar (PDA) plates and kept at $4{ }^{\circ} \mathrm{C}$.

\section{Screening Fusarium sp. Q7-31 as producing xylanase from 11 strains}

Among the 11 strains screened, based on its crude enzyme stability as well as its high activity. Loop-full of hyphae from each strain was inoculated in $50 \mathrm{~mL}$ of BLM, with $1 \%$ glucose as a carbon source. After culturing to saturation, about $50 \mathrm{~L}$ was transferred to $5 \mathrm{~mL}$ of BLM containing $0.3 \%$ rice plant powder and cultured at $28^{\circ} \mathrm{C}$. On Days 3 and 6 , the amounts of reducing sugars per milliliter of each culture medium were measured according to the dinitrosalicylic acid (DNS) method and compared among the 18 strains.

\section{Strains and cultivations}

The other 17 fungal strains (A, Morchella sp. M-1; B, Fusarium sp. Q7-31; C, Pestalotiopsis sp.; D, Fusarium sp. Q7-21; E, Trichoderma sp.; F, Penicillium sp.; G, Mucor sp. U1; H, Fusarium sp. F-2; I, Geotrichum sp.; J, Morchella sp. M2; K, Morchella sp. M-3) were stored in our Lab. The screening medium consisted of $0.6 \%$ peptone, $0.1 \% \mathrm{~K}_{2} \mathrm{HPO}_{4}$, $0.05 \% \mathrm{MgSO}_{4} \cdot 7 \mathrm{H}_{2} \mathrm{O}$, and $1 \%$ glucose $(\mathrm{pH}$ 7.0). The induced medium, producing xylanases, was composed of xylan $1 \%$, $\mathrm{NaNO}_{3} \quad 0.8 \%, \quad \mathrm{~K}_{2} \mathrm{HPO}_{4} \quad 0.1 \%, \quad \mathrm{MgSO}_{4} \cdot 7 \mathrm{H}_{2} \mathrm{O} \quad 0.05 \%, \mathrm{KCl}$ $0.05 \%, \mathrm{FeSO}_{4} \cdot 7 \mathrm{H}_{2} \mathrm{O} 0.001 \%$; and the $\mathrm{pH}$ was 4.5 . Erlenmeyer flasks $(150 \mathrm{ml})$ containing $50 \mathrm{ml}$ medium were inoculated at 25 ${ }^{\circ} \mathrm{C}$ shaking for 4 days.

Fusarium sp. Q7-31 was used as a source of xylanase and as a RNA and DNA donor strain. E. coli DH5aand E. coli BL21-CodonPlus (DE3)-RIL (Novagen, USA) were used as the hosts for cloning DNA sequencing and expression, respectively. pMD18-T and pGEX5x-1 vectors for cloning of PCR products were purchased from TaKaRa Biotechnology Co.

\section{DNS method to determine total reducing sugars}

Contents of reducing sugars in the liquid cultures and assay solutions were determined per the DNS method, with minor modification from the procedures described $(17,18,19)$. The DNS reagent consisted of $0.5 \%$ DNS, $0.025 \%$ sodium bisulfite, $0.5 \% \mathrm{NaOH}, 0.1 \%$ phenols, and $2.5 \mathrm{M} \mathrm{KOH}$. Mixtures of either $0.5 \mathrm{~mL}$ of fungus culture or enzyme reaction solution plus $0.1 \mathrm{~mL}$ of reagent were incubated for $10 \mathrm{~min}$ in boiling water. The total volume was brought to $1 \mathrm{~mL}$ by adding $0.4 \mathrm{~mL}$ of distilled water prior to reading Spectrophotometric absorbance at $575 \mathrm{~nm}$. 


\section{Identification of strain Fusarium sp. Q7-31}

The identification of the strain was based on standard morphological characterization and nucleotide sequence analysis of enzymatic amplified ITS rDNA, and the internal transcribed spacer (ITS) region including 5.8 S rDNA. Mycelia grown for $5 \mathrm{~d}$ on PDA plates were used for morphological measurements, such as hyphal width, spore formation, and spore shape. Genomic DNA was extracted from these mycelia by the CTAB method (25). ITS DNA was amplified by PCR with ITS5 forward primer 5'-GGAAGTAAAAGTCGTAACA AGG-3' and ITS4 reverse primer 5' -TCCTCCGCTTATTGAT ATGC-3', according to the procedure described by Van Burik (23). Sequences of the PCR products (Accession Number FJ646593) were analyzed through the NCBI BLAST database.

\section{Preparation of total RNA, Genomic DNA of Fusarium sp.Q7-31}

Mycelia of Fusarium sp.Q7-31, grown as previously described in the induced medium were collected by centrifugation at $3500 \times \mathrm{g}$ for $10 \mathrm{~min}$. To $100 \mathrm{mg}$ wet weight of pellet, $1 \mathrm{ml}$ Trizol was added in an adequate tube. The pellet was homogenized for $3-5 \mathrm{~min}$, and then let it strand at room temperature for $5 \mathrm{~min}$. then $0.2 \mathrm{ml}$ chloroform was added to the tube and the tube was subjected to vigorous vortex for $15 \mathrm{~s}$. The mixture was centrifuged at $12,000 \times \mathrm{g}$ for $15 \mathrm{~min}$ at $4^{\circ} \mathrm{C}$. The supernatant was collected and kept at room temperature for 10 $\min$. RNA was recovered by centrifuged at $12,000 \times \mathrm{g}$ for $10 \mathrm{~min}$ at $4{ }^{\circ} \mathrm{C}$ and washed twice with $75 \%$ ethanol. The RNA was kept at $-80^{\circ} \mathrm{C}$ in $75 \%$ ethanol for long-term storage. For the reverse transcription, the RNA pellet was air dried and dissolved in RNase-free water extracted using. RNA concentration was checked using spectrophotometer. Then isolate mRNA using Promega Large-Scale PolyA Tract System. Concentrate the mRNA with $3 \mathrm{M}$ sodium acetate and isopropanol. cDNA synthesis was carried out with cDNA synthesis kit. Preparation of genomic DNA was carried out according to CTAB method $(21,25)$.

\section{Primers for PCR amplification}

Two pairs of degenerated primer, F1 [GGCAACTTCGT CGGTGGTAAG], R1 [CAGTAGCCACGATCTGGTAGT], F2 [AACTTCGTCGGTGGTAAGGGT], R2 [AGTAACCCTC AGTAGCCACG], were designed according to eight different species organism of xylanases genes (Table2). Primer OT (Original name, oligo dT- $\mathrm{M}_{13}$ primer $\mathrm{M}_{4}$ ) was provided by TaKaRa RNA PCR Kit (AMV) Ver. 3.0. Primers RA [TACCTGGGTTCCATCCCTT] and RB [TCCCTTACCACC GACGAAGT] were used for Q7-31 5'RACE of xyn8 cDNA. Primer OF [ATGGTCTCCTTCAGGTTCCTTCTC] and OR [ATTAGATTGTAGATA CAAGTCGTT] were used for amplification of the genomic DNA encoding $x y n 8$.

\section{Reverse transcription of cDNA}

For cloning of partial cDNA by using degenerated primers, the total RNA was reverse transcribed with AMV reverse transcriptase by using primer OT. For cloning the $5^{\prime}$ end of the $x y n 8$ cDNA, reverse transcription was performed with the SMART PCR cDNA Synthesis Kit with M-MLV reverse transcriptase. The RB primer was added to the reaction solution after the end of reverse transcription and incubated at $42{ }^{\circ} \mathrm{C}$ for another $10 \mathrm{~min}$ so that the derived cDNA moleculers could have RB primer sequence at their 3' -end. All the reverse transcription reactions were performed following instructions provided by the manufacturers.

\section{DNA manipulation and $E$. coli transformation}

Digestion of DNA with restriction endonucleases EcoR I and Sal I , separation of fragments by agarose gel electrophoresis, ligation of DNA fragments, transformation of E.coli with plasmidic DNA and extraction of recombinant DNA were all performed according to the standard method (16). DNA fragments were recovered from agarose gels using the DNA Gel Extraction Kit of TaKaRa.

\section{DNA sequence analysis}

Products of the PCR reaction were cloned into pMD18-T 
Simple Vector (TaKaRa) and sequenced by Invitrogen (Shanghai, China) Co., Ltd 16. The sequence was analyzed using the software package DNAMAN 5.0 (Lynnon Bio-oft, USA) and the homology was analyzed in GenBank with the BLAST program. Properties of translated proteins based on the primary structure analysis were predicted using http://swissmodel.expasy.org/ on-line programs.

\section{Nucleotide sequence accession number}

The cDNA sequence of $x y n 8$ gene has been deposited in the GenBank database under accession numbers GQ249383 and ITS nucleotide sequence number is FJ646593.

\section{xyn8 expression and purification}

The cDNA fragment encoding the peptide of xylanase was amplied with OF and OR. The DNA fragment was ligated into pGEX5x-1 with restriction sites of EcoRI and Sal I to generate construct pGEX5x-1-xyn8. The expression construct was used to transform E.coli BL21-CodonPlus(DE3)-RIL for expression with the plasmid pGEX5x-1 for control. The transformants were screened on Luria-Bertani (LB) broth supplemented with $100 \mu \mathrm{g} / \mathrm{ml}$ Ampicillin and cultured with shaking at $37{ }^{\circ} \mathrm{C}$ overnight. Two microliters of seed culture were transferred into fresh medium and cultured until OD600 reached 0.8 , and IPTG (final concentration $0.4 \mathrm{mM}$ ) was added for induction. The bacterial cells were cultured for another $2 \mathrm{~h}$ before collection by centrifuge. SDS-PAGE was applied for confirmation of the expressed product.

After growth in liquid medium, cells were harvested by centrifugation, washed with cold 1xPBS buffer(137mM NaCL, 2.7mM KCL, 10mM Na2HPO4, 2mM KH2PO4; pH 6.0), and suspended in $20 \mathrm{ml}$ of cold PBS buffer. Cells were homogenized by ultrasonic treatment. Supernatant was obtained by centrifugation at $12,000 \times \mathrm{g}$ for $10 \mathrm{~min}$ at $4{ }^{\circ} \mathrm{C}$. The supernatant was used as crude enzyme for xylanase assay.

\section{SDS-PAGE and western blotting}

SDS-PAGE was performed on a $12.5 \%$ running gel (12) and resolved proteins were visualized by stainng with Coomassie Brilliant Blue G 250.

Transfer the proteins from the gel to a PVDF membrane, and incubate with GST Monoclonal Antibody (1:1000) for a night at $4{ }^{\circ} \mathrm{C}$. Decant and discard the antibody-buffer, rinse twice with $20-30 \mathrm{ml}$ of wash buffer to remove the majority of unbound antibody. Dilute secondary antibody 1:1000 with incubation buffer. Incubate for 1 hour at ambient temperature with gentle shaking. Wash the membrane with $20-30 \mathrm{ml}$ of wash buffer for 10 minutes at ambient temperature with gentle shaking. Detect the result by DAB Horseradish Peroxidase Color Development Kit.

\section{Determination of protein concentration}

Protein was determined by the Bradford assay (2) using bovine serum albumin as a standard.

\section{Xylanase activity assays}

Xylanase activity was measured using $1 \% \quad(\mathrm{w} / \mathrm{v})$ birchwood xylan (Sigma, USA) as a substrate in $50 \mathrm{mM}$ $\mathrm{Na}_{2} \mathrm{HPO}_{4}-$ citric acid buffer, $\mathrm{pH} 6.0$, at $40{ }^{\circ} \mathrm{C}$ for $10 \mathrm{~min}$. The liberation of reducing sugars was estimated by the dinitrosalicylic acid (DNS) method (13) using xylose as a standard. Reducing sugars were determined by measuring the absorption at $540 \mathrm{~nm}$ relative to a D-xylose standard. One unit of enzyme activity was defined as the quantity of enzyme required to liberate $1 \mu \mathrm{mol}$ of xylose equivalent per minute at $40{ }^{\circ} \mathrm{C}$, and specific activity was defined as units per mg protein (20). The results were means of duplicate determination on triple independent measurements.

\section{Temperature optimum and thermostability}

The temperature optimum was measured by performing the xylanase activity assay for $20 \mathrm{~min}$ at temperatures ranging from $15^{\circ} \mathrm{C}$ to $70^{\circ} \mathrm{C}$ under $\mathrm{pH} 6.0\left(\mathrm{Na}_{2} \mathrm{HPO}_{4}\right.$-citric acid buffer $)$. The thermostability of xylanase was investigated at temperatures $15^{\circ} \mathrm{C}, 20^{\circ} \mathrm{C}, 30^{\circ} \mathrm{C}, 40^{\circ} \mathrm{C}, 50^{\circ} \mathrm{C}, 60^{\circ} \mathrm{C}$ and $70{ }^{\circ} \mathrm{C}$ 
after incubation of the enzyme solutions in absence of substrate for 5min, 10min, 20min, 30min,40min, 50min, 60min, respectively. Residual activities were determined under xylanase activity assay conditions.

\section{pH optimum and stability}

The effect of $\mathrm{pH}$ on xylanase activity was evaluated (7) at the optimal temperature over a $\mathrm{pH}$ range of 3.0-10.0, using appropriate buffers $(50 \mathrm{mM}): \mathrm{Na}_{2} \mathrm{HPO}_{4}$-citric acid buffer $(\mathrm{pH}$ 3.0-6.0), $\mathrm{NaH}_{2} \mathrm{PO}_{4}-\mathrm{Na}_{2} \mathrm{HPO} 4$ buffer ( $\mathrm{pH}$ 6.0-8.0) and Tris-Hcl buffer (pH 8.0-9.0), glycin- $\mathrm{NaOH}$ (pH9.0-10.0) under xylanase activity assay conditions. Further study on the $\mathrm{pH}$ stability of the recombinant xylanase was carried out at $4^{\circ} \mathrm{C}$ by preincubation of the enzyme solutions in the aforementioned buffer systems in the absence of substrate at $4{ }^{\circ} \mathrm{C}$ for $1 \mathrm{~h}$. The $\mathrm{pH}$ values of various reaction solutions were adjusted to $\mathrm{pH}$ 6.0. Then they were subjected to xylanase activity assay.

\section{RESULTS}

\section{Isolation and identification of strain Fusarium sp. Q7-31}

Classification of the strain Q7-31 to a species of the genus Fusarium was manifested by analyses of its morphological features such as width and growth habit of mycelia and ITS sequences. Mycelia of Q7-31 grew vigorously to reach about 6 $\mathrm{cm}$ in diameter in 7 days on agar plates containing $0.3 \%$ rice plant powder as the sole carbon source. Mycelia of the strain Q7-31 typically appeared as white dry feathery villiform throughout the colony (Fig. 1A). They consisted of filamentous hyphae with septa (Fig. 1B). To determine growth rate of the strain Q7-31, its hyphae was inoculated on the center of basal medium agar plates containing $0.3 \%$ of rice powder and cultured at $28^{\circ} \mathrm{C}$. The colony diameter reached about $6 \mathrm{~cm}$ within 7 days of culture.

A genomic DNA region corresponding to the partial sequence of $18 \mathrm{~S}$ ribosomal RNA gene, the internal transcribed spacer 1 , the $5.8 \mathrm{~S}$ ribosomal RNA gene, the internal transcribed spacer 2 , and the partial sequence of $28 \mathrm{~S}$ ribosomal RNA gene was amplified by PCR using the genomic DNA isolated from the strain Q7-31 as a template. The sequence information of the PCR product was used for BLAST search in the NCBI databases. The BLAST result showed that the analyzed DNA region of Q7-31was 99\% identical to those of a few strains of Fusarium, Gibberella, and Cordyceps (Fig. 2). Considering of the morphological features and molecular analysis together, we classified Q7-31 as a strain of Fusarium species and deposited it to the Chinese Governmental Microorganism Conservation Center that complies with the Budapest Contract (or Protocol) on October 14, 2008 (deposition No: CGMCC2710).
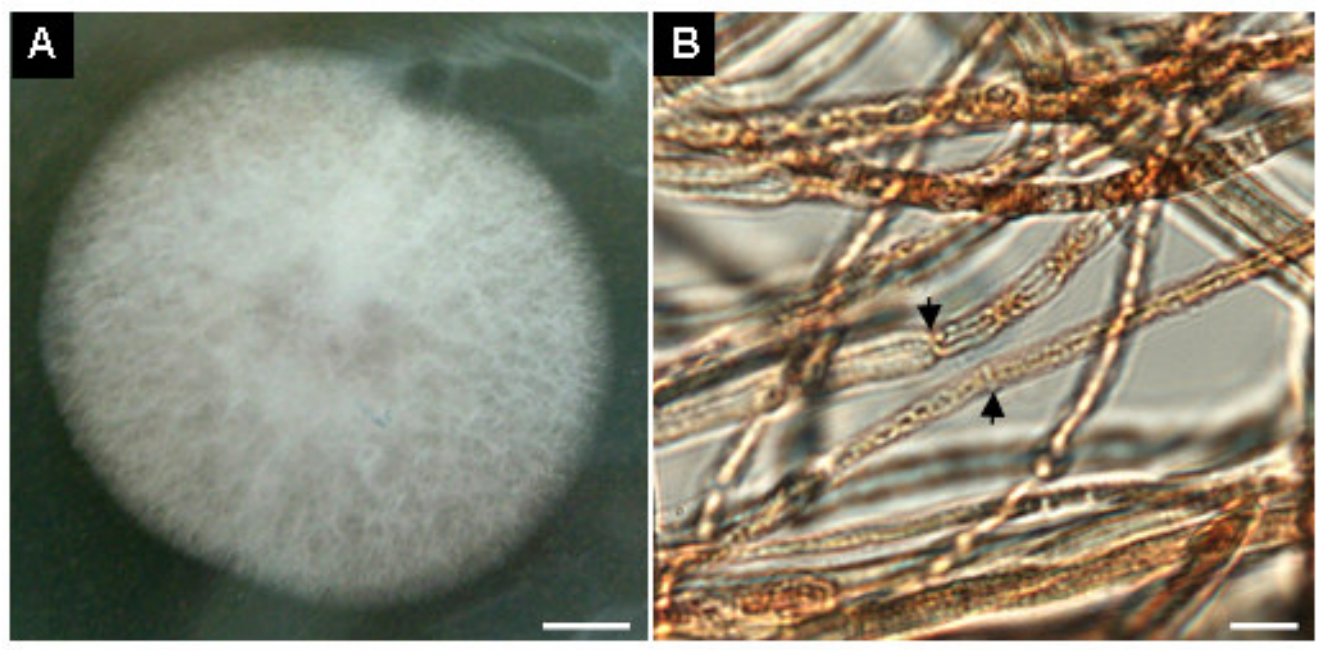

Figure 1. Growth habit and mycelia of Fusarium sp. Q7-31. (A) A loop-full of mycelia was inoculated onto center of agar plate containing $0.3 \%$ rice powder as sole carbon source. Image was taken after $5 \mathrm{~d}$ of culturing at $28^{\circ} \mathrm{C}$. (B) Light microscope image shoy 409 filamentous mycelia with septa (arrows). Scale bars are $1 \mathrm{~cm}$ and $5 \mu \mathrm{m}$ in (A) and (B), respectively. 


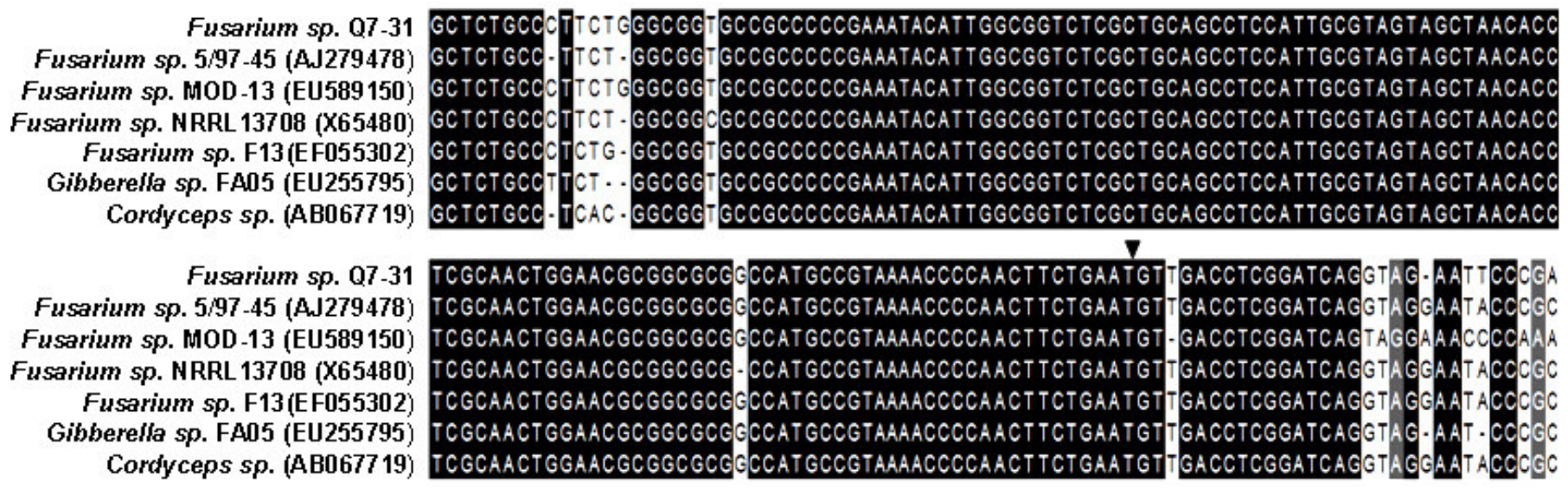

Figure 2. Alignment of Internal Transcribed Spacer sequences. To show regions with variation among species, only 159 bases of Fusarium sp. Q7-31 are aligned with those of closest species. Accession numbers for each reported species are in parentheses. Arrowhead indicates boundary between ITS2 and 28S ribosomal RNA gene.

\section{Selecting of strains Fusarium sp. Q7-31 producing xylanase}

Liquid cultures of total 11 fungus strains including Fusarium sp. Q7-31 with rice plant powder exhibited different degree of turbidity, reflecting difference in degradation of the powder (Fig. 3), including Q7-31 strains in Fig. 3(A) through (E) actively degraded the powder to a colloidal state, whereas the powder remained as unchanged granules in the cultures of strains in Fig. 3(I), (J), and (K). Cultures of some strains, i.e., Fig. 3(F), (G), and $(\mathrm{H})$, formed relatively large white aggregates of hyphae and partially digested plant powder. In addition to its culture appearance, the strain Q7-31 produced the highest levels of reducing sugars in both 3- and 6-day-old cultures among the strains, of which cultures became turbid within 3 days (Table 1). Comparison of reducing sugar contents, especially, in 6-day-old cultures distinguished the strain Q7-31 from other strains tested. Based on these results, we selected the strain Q7-31 for further characterization with respect to xylanase gene (Table 2).

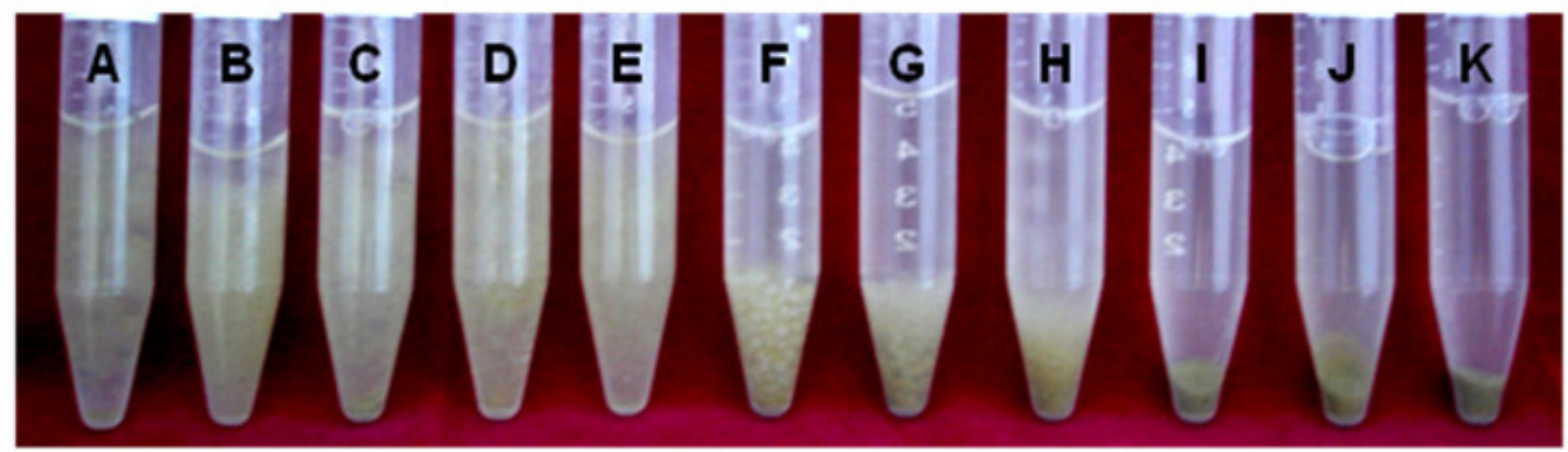

Figure 3. Liquid culture of fungus strains with different degradabilities.

Medium was supplemented with $0.3 \%$ rice cell wall powder as sole carbon source. Fungus strains were cultured for $3 \mathrm{~d}$ at $28^{\circ} \mathrm{C}$ with 100×g shaking. A, Morchella sp. M-1; B, Fusarium sp. Q7-31; C, Pestalotiopsis sp.; D, Fusarium sp. Q7-21; E, Trichoderma sp.; F, Penicillium sp.; G, Mucor sp. U-1; H, Fusarium sp. F-2; I, Geotrichum sp.; J, Morchella sp. M-2; K, Morchella sp. M-3. 
Table 1. Screening of fungus strains for plant cell wall-degrading activity. Each strain was cultured in a basic liquid medium containing $0.3 \%$ rice powder for 3 or 6 days. Contents of total reducing sugars were determined by the DNS method. Degree of rice powder degradation in the cultures was scored by arbitrary observation as follows: H, highly (i.e., Fig. 3A-E) ; M, moderately (i.e., Fig. 3F and G); P, poorly (i.e., Fig. 3H), and N, not detectably degraded (i.e., Fig. 3I, J, and K).

\begin{tabular}{lccccc}
\hline \multirow{2}{*}{ Fungus species } & Strain & \multicolumn{2}{c}{ A $575^{2}$ for total reducing sugars } & \multicolumn{2}{c}{ Rice powder degradation } \\
\cline { 5 - 7 } & & Day 3 & Day 6 & Day 3 & Day 6 \\
\hline \multirow{2}{*}{ Fusarium sp. } & $\mathrm{Q} 7-21$ & $0.12 \pm 0.023$ & $0.27 \pm 0.009$ & $\mathrm{H}$ & $\mathrm{H}$ \\
& $\mathrm{Q} 7-31$ & $0.24 \pm 0.004$ & $0.34 \pm 0.029$ & $\mathrm{H}$ & $\mathrm{H}$ \\
& $\mathrm{F}-2$ & 0 & 0.05 & $\mathrm{H}$ & $\mathrm{H}$ \\
Geotrichum sp. & $\mathrm{G}-1$ & $0.13 \pm 0.029$ & 0.03 & $\mathrm{~N}$ & $\mathrm{P}$ \\
Morchella sp. & $\mathrm{M}-1$ & 0.06 & 0.04 & $\mathrm{H}$ & $\mathrm{H}$ \\
& $\mathrm{M}-2$ & 0.01 & 0 & $\mathrm{~N}$ & $\mathrm{P}$ \\
& $\mathrm{M}-3$ & 0.04 & 0.02 & $\mathrm{~N}$ & $\mathrm{P}$ \\
& & & & & \\
Mucor sp. & $\mathrm{U}-1$ & $0.20 \pm 0.009$ & 0.05 & $\mathrm{P}$ & $\mathrm{M}$ \\
& & & & & \\
Penicilium sp. & $\mathrm{P}-1$ & $0.10 \pm 0.005$ & 0.05 & $\mathrm{M}$ & $\mathrm{H}$ \\
Pestalotiopsis sp. & $\mathrm{E}-1$ & 0.06 & $0.19 \pm 0.015$ & $\mathrm{H}$ & $\mathrm{H}$ \\
Trichoderma sp. & $\mathrm{T}-1$ & 0.06 & $0.11 \pm 0.028$ & $\mathrm{H}$ & $\mathrm{H}$ \\
\hline
\end{tabular}

Table 2. Xylanase genes from 8 different organism of Species of Gene Bank

\begin{tabular}{|c|c|c|c|c|c|c|}
\hline \multirow{2}{*}{$\begin{array}{l}\text { SeqA } \\
===\end{array}$} & Name & Len (nt) & SeqB & Name & Len (nt) & Score \\
\hline & $============$ & $=======$ & $====$ & $============$ & $======$ & $=====$ \\
\hline 1 & EF208066xyn1 & 846 & 2 & AF155594xyn2 & 698 & 48 \\
\hline 1 & EF208066xyn1 & 846 & 3 & AF246831xy14 & 696 & 64 \\
\hline 1 & EF208066xyn1 & 846 & 4 & AF246830xy15 & 888 & 44 \\
\hline 1 & EF208066xyn1 & 846 & 5 & U10298xynA & 666 & 41 \\
\hline 1 & EF208066xyn1 & 846 & 6 & U24191xynB & 786 & 44 \\
\hline 1 & EF208066xyn1 & 846 & 7 & AY156910 & 841 & 45 \\
\hline 1 & EF208066xyn1 & 846 & 8 & Z68891 & 684 & 61 \\
\hline 2 & AF155594xyn2 & 698 & 3 & AF246831xy14 & 696 & 71 \\
\hline 2 & AF155594xyn2 & 698 & 4 & AF246830xy15 & 888 & 52 \\
\hline 2 & AF155594xyn2 & 698 & 5 & U10298xynA & 666 & 40 \\
\hline 2 & AF155594xyn2 & 698 & 6 & U24191xynB & 786 & 59 \\
\hline 2 & AF155594xyn2 & 698 & 7 & AY156910 & 841 & 50 \\
\hline 2 & AF155594xyn2 & 698 & 8 & Z68891 & 684 & 63 \\
\hline 3 & AF2 46831xy14 & 696 & 4 & AF246830xy15 & 888 & 51 \\
\hline 3 & AF2 46831xy14 & 696 & 5 & U10298xynA & 666 & 33 \\
\hline 3 & AF2 46831xy14 & 696 & 6 & U24191xynB & 786 & 51 \\
\hline 3 & AF2 46831xy14 & 696 & 7 & AY156910 & 841 & 50 \\
\hline 3 & AF2 46831xy14 & 696 & 8 & Z68891 & 684 & 64 \\
\hline 4 & AF246830xy15 & 888 & 5 & U10298xynA & 666 & 48 \\
\hline 4 & AF2 46830xy15 & 888 & 6 & U24191xynB & 786 & 45 \\
\hline 4 & AF2 46830xy15 & 888 & 7 & AY156910 & 841 & 51 \\
\hline 4 & AF2 46830xy15 & 888 & 8 & Z68891 & 684 & 66 \\
\hline 5 & U10298xynA & 666 & 6 & U24191xynB & 786 & 59 \\
\hline 5 & U10298xynA & 666 & 7 & AY156910 & 841 & 50 \\
\hline 5 & U10298xynA & 666 & 8 & Z68891 & 684 & 48 \\
\hline 6 & U24191xynB & 786 & 7 & AY156910 & 841 & 70 \\
\hline 6 & U24191xynB & 786 & 8 & Z68891 & 684 & 65 \\
\hline 7 & AY156910 & 841 & 8 & Z68891 & 684 & 55 \\
\hline
\end{tabular}




\section{Cloning of cDNA encoding the $x y n 8$ of $F$. sp Q7-31}

For the first step, we tried to obtain a partial cDNA sequence of the $x y n 8$ starting from primer we had. Two degenerated primers were synthesized corresponding to the conserved parts of the several amino acid residues. Primer OT was used as the primer for reverse transcription of the firststrand cDNA from total RNA. The first-strand cDNA was used as the template for amplification with primers F1/R1 and F2/R2. A 450-bp DNA fragment band was amplified. This band was agarose gel-purified and cloned into pMD18-T Simple Vector. The nucleotide sequence was subsequently determined. The insert was $450 \mathrm{bp}$ in length and consisted of partial $x y n 8 \mathrm{cDNA}$ and $31 \mathrm{bp}$ of primer OT.

Next, we moved on to obtain the full-length cDNA of the xyn 8 by a modified 5'RACE approach based on the characteristics of M-MLV reverse transcriptase (23). After reverse transcription, the cDNA was used as the template for PCR amplification with primers RB and RA. A fragment was obtained as the major PCR product. The PCR products were cloned into pMD18-T Simple Vector and the nucleotide sequence was subsequently determined. By aligning the nucleotide sequence of the two fragments, the full-length cDNA of the xylanase of 693bp was obtained (Fig. 4).

The coding sequence consisted of a 230 amino acids $x y n 8$ with a calculated molecular mass of $25.7 \mathrm{kDa}$. These features are in good agreement with the molecular mass determined by SDS-PAGE.

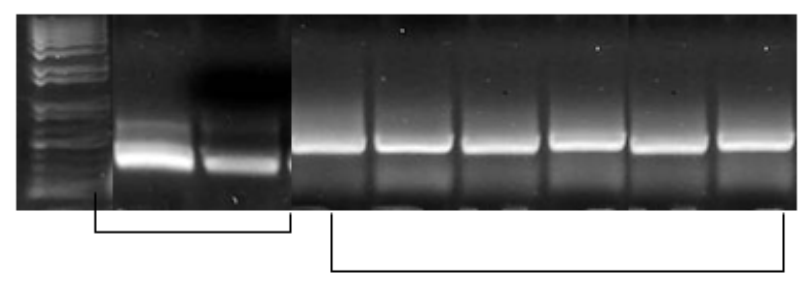

3' RACE

5' RACE

Figure 4. Cloning xylanase gene from Fusarium sp Q7-31. Lane 1: DNA marker; Lane 2-3: PCR of 3' RACE of xylanase cDNA Lane 4-9: PCR amplified 5' RACE technique.

\section{Cloning of the $x y n 8$ gene}

To confirm the identity of the cDNA of the $x y n 8$, effort was made to clone the genomic DNA of the $x y n 8$ gene. The $x y n 8$ gene was amplified from genomic DNA of $F$. sp Q7-31, with primers OF and OR. The sequence of the 804-bp DNA fragment contained the complete nucleotide sequence of the cDNA with two short intervenings by two introns of 56bp and 55bp as indicated in Fig.5 and Fig.6.

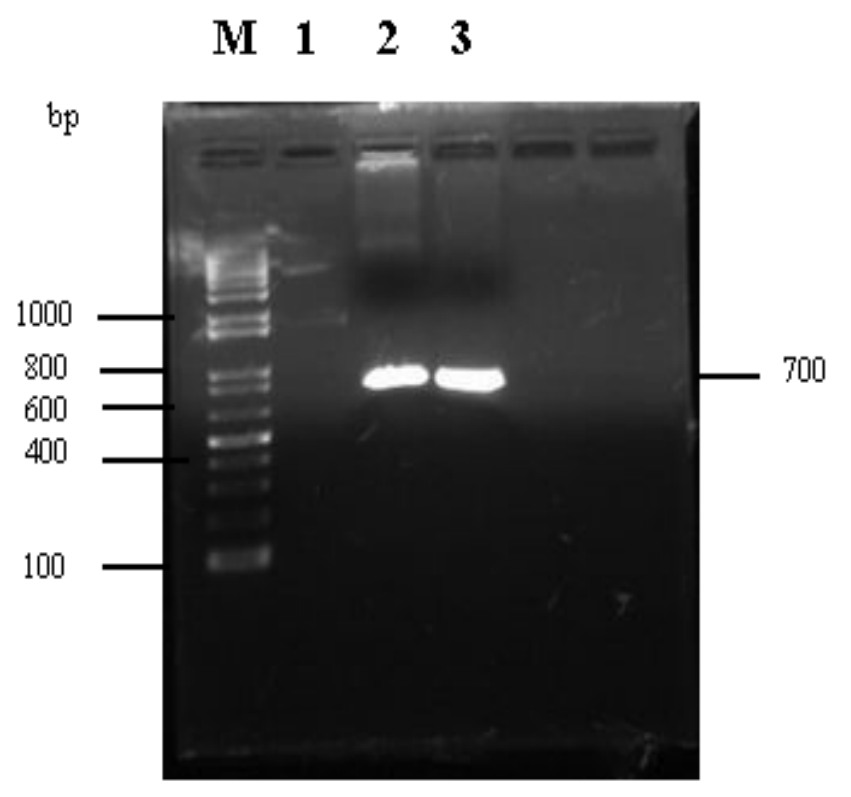

Figure 5. Cloning of the ORF sequance. Using the primers F1 and R1for PCR with restriction enzyme cutting site in the 5, end, clone the ORF for expression in Ecoli. PCR products were used to construct an expression plasmid and translate into Ecoli.BL21 (DE3). M: PCR fragment. 1: blank. 2-3: PCR fragment. 
7

2

148 AAC GGC TAC TTC TAC TCT TGG TGG AGC GAT GGC GGT GGT TAC GCT CAG TACAAG ATG GGT GAG GGCAGC CAA

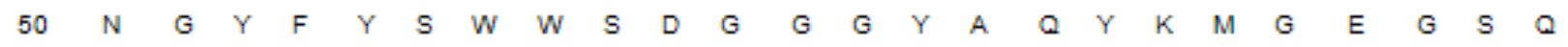

220 TAC TCG GTT GAG TGG CGAAACACT GGT AAC TTT GTC GGT GGCAAG GGATGGAAC CCA GGT ACT GGC CGg

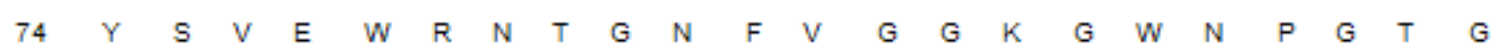

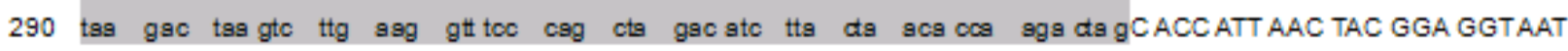

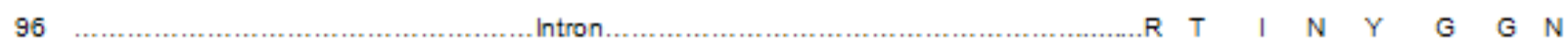

367 TTC AGC CCT CAG GGT AAC GGC TAC CTT GCT GTC TAT GGC TGGACT CGT GGC CCT CTC GTC GAG TAC TAT g t9C

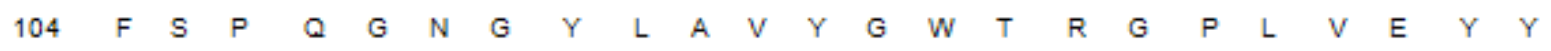

440 get atc the tos goc sag att csa the thg the cts act atc goc toc c9g GTCATT GAGAACTTCGGAACC TAC

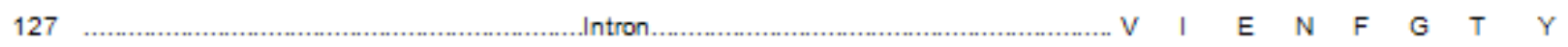

515 AAC CCC GCC AGC GGT GCT CAG CAC AAG GGAACT GTT TACACT GAC GGA GAC ACC TAC GAC CTC TAC CAG TCC

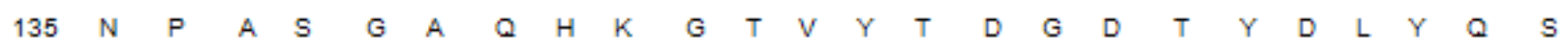

587 ACC CGA TAC CAG CAG CCT TCC ATC GAC GGT GTC CAG ACC TTC AAC CAG TAC TGG TCAATC CGC CGC AAC AAG

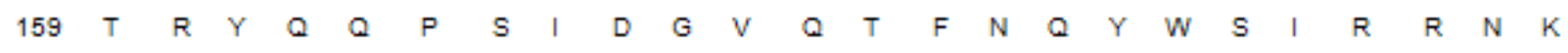

659 CGC GTT GGC GGC TCC GTCAACATG CAG AAC CACTTC AAC GCG TGG AAC CAG GCC GGC ATG CGC CTT GGT AAC

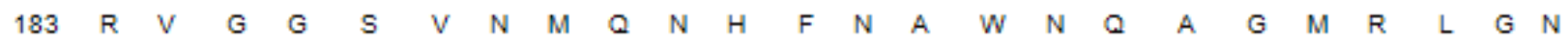

731 CAC TAC TAC CAAATC GTG GCT ACG GAG GGT TAC CAGAGC AGC GGC TCT TCT AAC ATC TAT GTT CAG AACAAG TAA

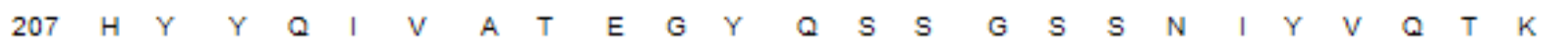

Figure 6. Nucleotide sequence of the Xyn8 gene and its deduced amino acid. DNA sequence of two introns is shown in lowercase letters and grey boxes. The bold letters in boxes, ATG and TAA, indicate the start codon and stop codon.

\section{DNA sequence analysis of the $x y n 8$ gene}

The predicted peptide consisted of 230 amino acids with the theoretical M.W. of $25.7 \mathrm{kDa}$. Amino acid homology alignment of the predicted Xyn8 with other four xylanases from Fusarium oxysporum f. sp., Glomerella graminicola, Verticillium dahliae, Verticillium albo-atrum was carried out (Fig. 7). The identities between $F$. sp. Q7-31 with $F$. oxysporum f. sp (AAK 27975.1), Glomerella graminicola (EFQ30380.1), Verticillium dahliae (ABE02800.1), V. alboatrum (XP_003006739.1) were 87\%, 78\%, 74\%, 74\%, respectively.
The phylogenetic analysis of the xylanases included 25 known different amino acid sequences of xylanase and was complied using the data base ( Fig.8). The phylogenetic tree of the xylanases was then constructed by MEGA 3.1, as shown in Fig. 9. According to this phylogenetic tree, the Xyn8 is genetically closely related to the hypothesis protein of Gibberella zeae (89\%), and xylanase F. oxysporum (87\%). We found that the topology of the evolutionary tree of the Xyn8 is quite similar to that of the other GHF 11 xylanases, so that the Xyn8 should be classified into the family 11 glycosyl hydrolases. 


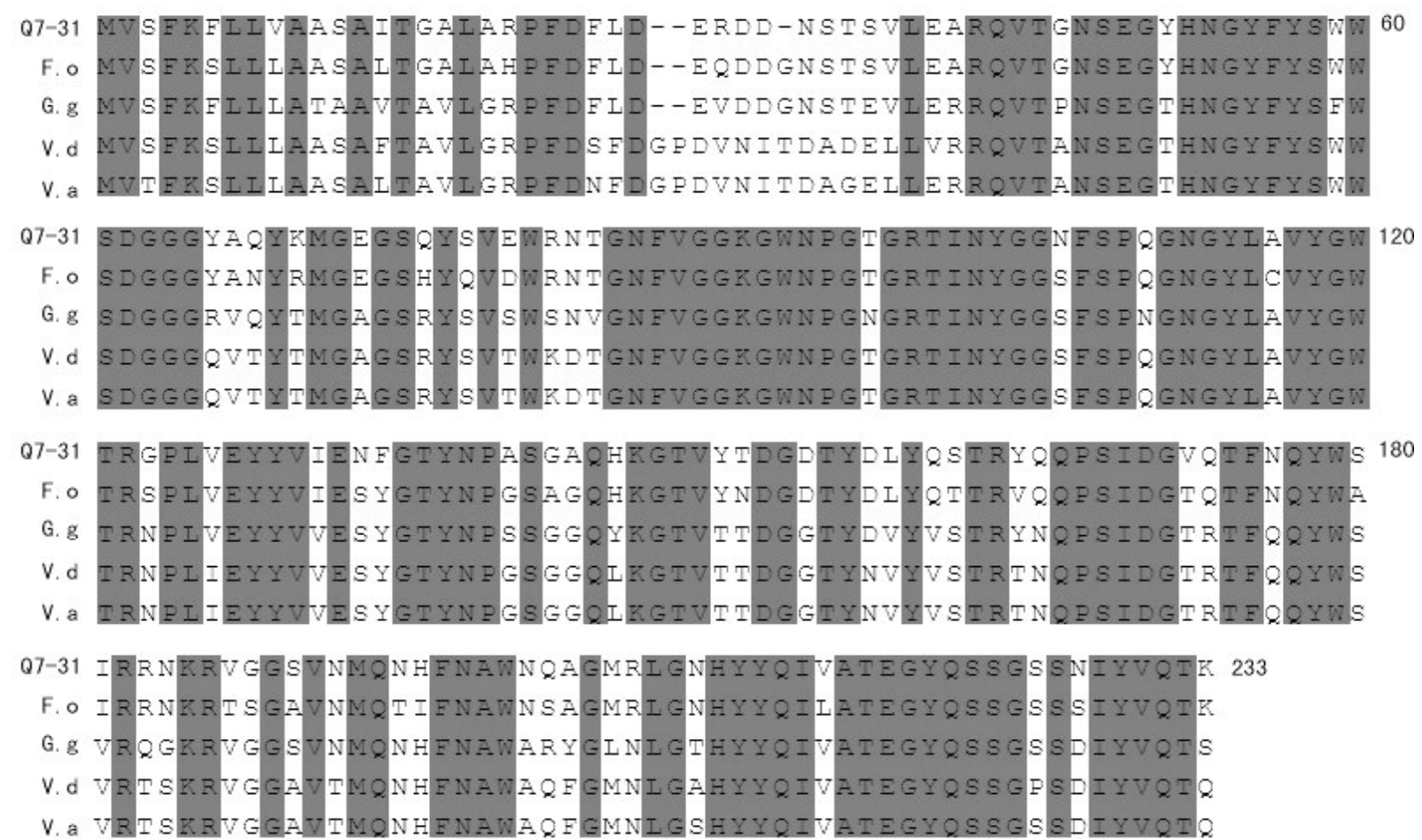

Figure 7. Comparison of Xyn8 to other microbial xylanases. Abbreviations: Fusarium oxysporum f. sp., Glomerella graminicola, Verticillium dahliae, Verticillium albo-atrum. The conserved and similar amino acids in five xylanases are indicated by solid and same color boxes, respectively.

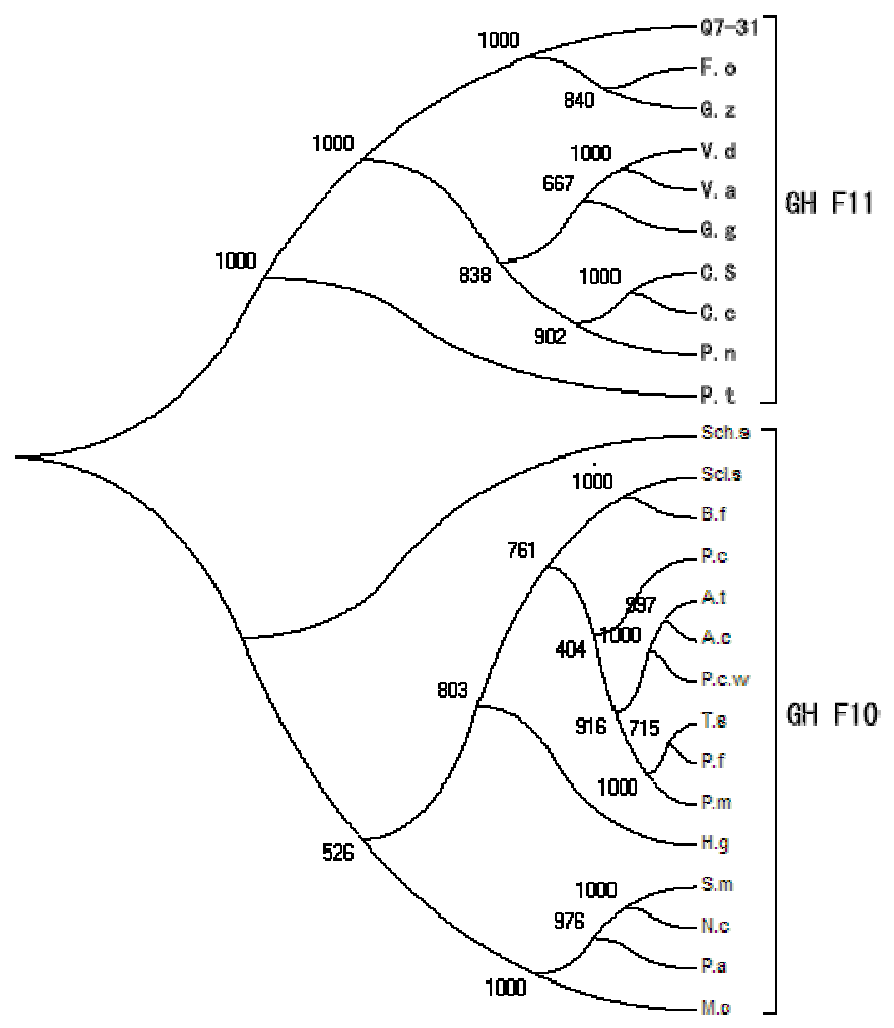

Figure 8. Neighbor-joining (NJ) phylogenetic tree using MEGA 3.1 showing the evolutionary relatedness and levels of homology between the xylanase amino acid sequences. The estimated genetic distance between sequences is proportional to the lengths of the horizontal lines connecting one sequence to another. This is an unrooted tree. Bootstrap values of the major branch points are shown; they represent the number of times the group consisting of the species to the right of that branch occurred among 100 trees. The sequences are of the following proteins: F.o., Fusarium oxysporum; G.g., Glomerella graminicola; V.d., Verticillium dahliae; V.a., Verticillium albo-atrum; C.s., Cochliobolus sativus; C.c., Cochliobolus carbonum; P.t., Pyrenophora tritici-repentis; P.n., Phaeosphaeria nodorum; G.z., Gibberella zeae; Sch.s., Scheffersomyces stipitis; H.g., Humicola grisea; Scl.s., Sclerotinia sclerotiorum; B.f., Botryotinia fuckeliana; A.t., Aspergillus terreus; T.s., Talaromyces stipitatus; P.m., Penicillium marneffei; P.f., Penicillium funiculosum; M.o., Magnaporthe oryzae; P.c.w., Penicillium chrysogenum Wisconsin; S.m., Sordaria macrospore; P.a., Podospora anserine; A.c., Aspergillus clavatus; N.c., Neurospora crassa; P.c., Phanerochaete chrysosporium. 


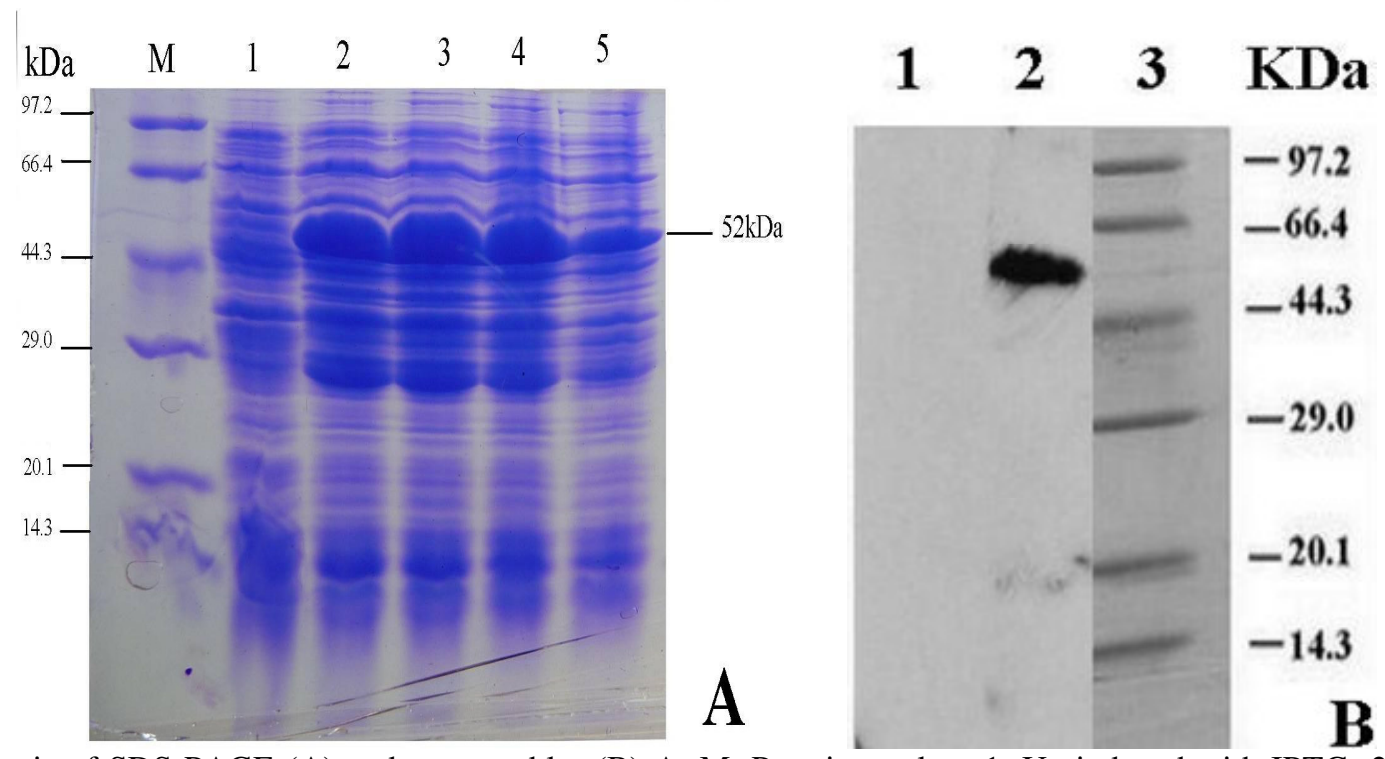

Figure 9. Analysis of SDS-PAGE (A) and western blot (B) A: M. Protein marker; 1. Un-induced with IPTG; 2, 3, 4, and 5: induced for by IPTG; B: 1, pGEX5x-1+BL21; 2, pGEX5x-1-xyn8+BL21; 3.

\section{Expression of Xyn8 in E. coli}

To further test if the cloned sequence truly represents $F$. sp. Q7-31. Primers OF and OR were applied to amplify the peptide encoding cDNA with adequent restriction enzyme sites so that the cDNA could be inserted into expression vector pGXE5x-1 in the right reading frame. Because of the presence of the GST-tag fusion peptide in expression vector pGXE5x-1, the recombinant protein had a $26 \mathrm{kDa}$ peptide. As shown in Fig. 9(A), an efficiency of Xyn8 protein expression was achieved with pGXE5x-1. The recombinant protein showed a M.W. of about $52 \mathrm{kDa}$ which was close to the theoretical value.

Western blotting and SDS-PAGE showed that the cell extracts from E. coli BL21CodonPlus(DE3)-RIL harboring pGXE5x-1-xyn8 exhibited a clear band with a molecular weight about 52kDa (Fig. 9, A-Lane2- 5, B-Lane 2), which was a fusion hybrid protein and has the same size as estimated from the deduced amino acid sequence of the fusion region in pGXE5x-1-xyn8. The expression of the solubility fusion hybrid protein could be induced by IPTG. A maximum activity of 2.34U/ mg was obtained from cellular extract of E. coli BL21CodonPlus (DE3)-RIL harboring pGXE5x-1-xyn8 (table 3). These predictions are consistent with experimental data previously obtained from the GST-Xyn8 fusion protein (7).

Table 3. Characteristics of xylanase fusion protein of Xyn8

\begin{tabular}{|c|c|c|c|c|c|}
\hline Enzymes & $\mathrm{pH}$ optimum & $\begin{array}{l}\mathrm{pH} \text { stability } \\
\text { of } 50 \% \text { activity }\end{array}$ & $\begin{array}{l}\text { Temperature } \\
\text { optimum }(\mathrm{C})\end{array}$ & $\begin{array}{l}\text { Temperature stability } \\
\text { of } 50 \% \text { activity }\left({ }^{\circ} \mathrm{C}\right)\end{array}$ & $\begin{array}{l}\text { Enzyme } \\
\text { activity }\end{array}$ \\
\hline Crude Xylanase & 5.5 & $5.0-12.0$ & 50 & $<45$ & $11.5(\mathrm{u} / \mathrm{mL})$ \\
\hline \multicolumn{6}{|l|}{ Recombinase } \\
\hline GST-Xylw8 & 6 & $5.0-9.0$ & 40 & $<20$ & $2.34 \mathrm{U} / \mathrm{mg}$ \\
\hline
\end{tabular}




\section{Properties of Xyn8}

From the $\mathrm{pH}$ profile, the $\mathrm{pH}$ for optimal activity of Xyn8 was determined to be $\mathrm{pH} 6.0$, with $50 \%$ of maximum activity being retained between $\mathrm{pH} 5.8$ and $\mathrm{pH} 9.0$ (Table 3). The apparent optimal temperature for enzyme activity at $\mathrm{pH} 6.0$ was $40{ }^{\circ} \mathrm{C}$. Crude xylanase from Q7-31 was used to evaluate its biochemical properties.

\section{DISCUSSION}

The Qinghai-Tibet Plateau is located in east Asia and represents a unique permafrost environment, being a result of high elevation caused by land uplift. However, its microbiology remains largely unexplored to date. Zhang G reported that the total 33 analyzed isolates from Qinghai-Tibet Plateau, 9 isolates related to 8 genera might be new taxa, it suggested that the Qinghai-Tibet Plateau permafrost region is a specific ecologic niche that accommodates an original microbial assemblage $(11,27)$. Yu-Qin Zhang (26) reported there was abundant actinobacterial species diversity in the soil samples from the Qinghai-Tibet plateau, including xylanaseproducing microorganisms (2010). No xylanase-producing fungi have been reported in the Qinghai-Tibet plateau. In this study, we isolated and identified a xylanse-producing strain of Fusaurium sp.Q7-31 from a morchella fruiting body in the Qinghai-Tibet plateau. The ITS rDNA sequence of Fusaurium sp.Q7-31 showed high identity with Fusarium oxysporum, there are reports on xylanses produced by Fusarium oxysporum(), while the gene Xyn8 from Fusaurium sp.Q7-31 is deferent from other reports. The gene Xyn 8 from Fusaurium sp.Q7-31 encodes a GHF11 xylanse.

Xyn8 has relatively the highest sequence identity to Xyl5 (87\%) from $F$. oxysporum (5), but the properties of these two enzyme are distinct. $X y l 5$ resulting from differential splicing of the third intron, while $X y n 8$ resulting from differential splicing of the second intron.

The cloning of a novel gene depends largely on the combination of DNA library construction and the screening of genes. Various methods have been developed to amplify the process, such as screening of an expression DNA library or genomic DNA library with antibodies or detecting specific enzyme activity of the target protein; however, all the present methods are still time-consuming and laborious.

In this work, cloning the cDNA and the gene of the Xyn8 from $F$. sp Q7-31 were achieved by using three steps of PCR. The first step was to use degenerated primers for amplification of cDNA. The second step was to obtain the full-length cDNA by a modified 5' RACE approach. The third step was to obtain the introns sequence in genomic DNA corresponding to the full-length cDNA. It has been reported that the xylanases can be divided into two major families based on their 3D structures, GHF 10 and GHF 11. From the prediction of tertiary structure, we found that the 3D structure of the Xyn8 of $F$. sp. Q7-31 was mostly similar to some xylanases of GHF 11. Therefore, we concluded that Xyn8 belonged to the family 11 glycosyl hydrolases.

The favorable properties of Xyn8, such as high activity over a wide temperature range and so on, make this xylanase promising for various applications in the biofuel industries.

\section{ACKNOWLEDGEMENTS}

Project was supported by the china National Science Foundation (30860048). This research was supported by Professor Ge Rili and Liu Yujiao who both come from Qinghai University. We also should thank the station master Shen Zhixin.

\section{REFERENCES}

1. Alconada TM, Martínez MJ. (1994). Purification and characterization of an extracellular endo-1,4-beta-xylanase from Fusarium oxysporum f. sp. melonis. FEMS Microbiol Lett. 15;118(3):305-10.

2. Bradford, M.M. (1976). A rapid sensitive method for the quantitation of microgram quantities of protein utilizing the principle of protein-dye binding. Anal. Biochem. 72: 248-254.

3. Christakopoulos P, Nerinckx W, Kekos D, Macris B, Claeyssens M. (1997). The alkaline xylanase III from Fusarium oxysporum F3 belongs 
to family F/10 Aug 7;302(3-4):191-5. Carbohydr Res.

4. Christakopoulos, P.; Nerinckx, W.; Kekos, D.; Macris, B.; Claeyssens, M. (1996). Purification and characterization of two low molecular mass alkaline xylanases from Fusarium oxysporum F3. Journal of Biotechnology. 51: 181-189.

5. Esperanza Gómez-Gómez, M.C.; Isabel, G.; Roncero. (2001). Molecular characterization of a novel endo- $\beta-1,4$-xylanase gene from the vascular wilt fungus Fusarium oxysporum. Current Genetics. 40: 268-275.

6. Esperanza Gómez-Gómez, M.C.; Ruiz-Roldan, A.; Di Pietro, M.I.G.; Roncero.; Hera, C. (2002). Role in Pathogenesis of Two Endo- $\beta-1,4-$ xylanase Gene from the Vascular Wilt fungus Fusarium oxysporum. Fungal Genet Biol. 35, 213-222.

7. Fu, D.D.; Li, A.J.; Xie, H.; Wu, M.C. (2006). Purification and properties of xylanase from Aspergillus usamii. Food. Sci. 27, 116-120.

8. Gómez-Gómez E, Isabel M, Roncero G, Di Pietro A, Hera C. (2001) Molecular characterization of a novel endo-beta-1,4-xylanase gene from the vascular wilt fungus Fusarium oxysporum. Curr. Genet. 40 (4), 268275.

9. Gómez-Gómez E, Ruíz-Roldán MC, Di Pietro A, Roncero MI, Hera C. (2002) Role in pathogenesis of two endo-beta-1,4-xylanase genes from the vascular wilt fungus Fusarium oxysporum. Fungal Genet Biol. Apr;35(3):213-22.

10. Jorge I, de la Rosa O, Navas-Cortés JA, Jiménez-Díaz RM, Tena M. (2005) Extracellular xylanases from two pathogenic races of Fusarium oxysporum f. sp. ciceris: enzyme production in culture and purification and characterization of a major isoform as an alkaline endo-beta-(1,4)xylanase of low molecular weight. Antonie Van Leeuwenhoek. Jul;88(1):48-59.

11. Gaosen Zh., Xiaojun M., Fujun N., Maoxing D., Huyuan F., Lizhe A. and Guodong Ch. (2007). Phylogenetic diversity of bacteria isolates from the Qinghai-Tibet Plateau permafrost region. Canadian J. Microb.

12. Laemmli, U.K. (1970). Cleavage of structural proteins during the assembly of the head of bacteriophage T4. Nature. 227: 680-685.

13. Miller, GL. (1959). Use of dinitrosalicylic acid reagent for determination of reducing sugars. Anal. Chem. 31: 426-428.

14. Ruiz Roldan, M.C.; Di Pietro, A.; Roncero, M.I.G. (1997). Purification and characterization of an acidic endo- $\beta-1,4$-xyalnase from the tomato vascular pathogen Fusarium oxysporum f.sp. lycopersici. FEMS Microbiol Lett. 148: 75-82.
15. Ruiz Roldan, M.C.; Di Pietro, A.; Huertas Gonzalez, M.D.; Roncero M.I.G. (1999). Two xylanase genes of the vascular wilt pathogen Fusarium oxysporum are differentially expressed during infection of tomato plants. Mol. Genet. 261: 530-536.

16. Sambrook, J.; Fritsch, E.F.; Maniatis, T. (1989). Molecular Cloning: a Laboratory Manual, seconded. Cold Spring Harbor Laboratory Press, Cold Spring Harbor, New York.

17. Sambrook, J.; Fritsch, E.F.; Maniatis, T. (2001). Molecular Cloning: A Laboratory Manual. Cold Spring Harbor Laboratory Press, Cold Spring Harbor, New York.

18. Sapag, A.; Wouters, J.; Lambert, C. (2002). The endoxylanases from family11: computer analysis of protein sequences reveals important structural and phylogenetic relationship. J. Biotechnol. 95, 109-131.

19. Sengupta, S.; Jana, M.L.; Sengupta, D.; Naskar, A.K. (2000). A note on the estimation of microbial glycosidase activities by dinitrosalicylic acid reagent. Appl. Microbiol. Biot. 53: 732- 735.

20. Shao, W.; Wiegel, J. (1992). Purification and characterization of a thermostable xylosidase from Thermoanaerobacter ethanolicus. $J$. Bacteriol. 174, 5848-5853.

21. Van Burik, J.A.; Schreckhise, R.W.; White, T.C.; Bowden, R.A.; Myerson. D. (1998). Comparison of six extraction techniques for isolation of DNA from filamentous fungi. Med. Mycol. 36: 299- 303.

22. Vallander, L.; Eriksson, K. E. L. (1990). Production of ethanol from lignocellulosic materials: State of the art. Adv. Biochem. Eng. Biotechnol. 42: 63-95.

23. Verma, I.M. (1977). Reverse transcriptase-The Enzymes. Academic Press, New York.

24. Walton, J.D. (1994). Deconstructing the plant cell wall. Plant Physiol. 104: 1113-1118.

25. Yang, G.L.; An, Q.; Li, J.; Lin, W.; Liu, L.; Lin, X. (2007). Genotyping of Trichophyton rubrum by analysis of ribosomal-DNA intergenic spacer regions. Mycopathologia. 164: 19- 25.

26. Yu-Qin, Zh.; Hong-Yu, L.; Jie, Ch.; Li-Jie, Y.; Wei, S. (2010). Diversity of culturable actinobacteria from Qinghai-Tibet plateau, China. Antonie van Leeuwenhoek, 98, : 2, s: 213-223

27. Zhang, G.; Niu, F.; Ma, X.; Liu, W.; Dong, M.; Feng, H.; An, L.; Cheng, G. (2007). Phylogenetic diversity of bacteria isolates from the QinghaiTibet Plateau permafrost region. Can J Microbiol. Aug;53(8):1000-10. 